\title{
Environmental Policies and Strategies in Nigeria Oil and Gas Industry: Gains, Challenges and Prospects
}

\author{
Ephraim Ikechukwu Elenwo' ${ }^{1}$ Justine Ayaegbunem Akankali2 \\ ${ }^{1}$ Department of Geography and Environmental Management, Faculty of Social Science, University of Port \\ Harcourt, Choba, Nigeria \\ ${ }^{2}$ Department of Fisheries, Faculty of Agriculture, University of Port Harcourt, Choba, Nigeria \\ Email: ephraimelenwo@gmail.com, justinoy3k@yahoo.com
}

Received 6 September 2014; revised 8 October 2014; accepted 24 October 2014

Copyright (C) 2014 by authors and Scientific Research Publishing Inc.

This work is licensed under the Creative Commons Attribution International License (CC BY). http://creativecommons.org/licenses/by/4.0/

(c) (i) Open Access

\begin{abstract}
The paper reviews environmental policies and strategies in the Nigerian oil and gas industry sector, assessing its efficiency, challenges and prospects. Essentially, the study established that the Environmental Policies and Strategies of Nigeria Oil and Gas Industry have impacted positively on the Nigerian environment over the years, especially in the area of awareness creation for all stake-holders. In terms of challenges, inefficiency of the regulators due to inadequacy of logistics, poor environmental data base, duplication and overlaps of regulators functions are some of the challenges identified. The prospect of environmental policies and strategies in Nigeria is generally considered to be bright, considering the fact that the industry is still evolving. Relevant recommendations were made on how to achieve improvements.
\end{abstract}

\section{Keywords}

Environment, Policies, Strategies, Nigeria, Oil and Gas Industry

\section{Introduction}

It is very important to note that each time environmental issues are mentioned in Nigeria, the oil and gas industry readily comes to mind. The reason for this is that the oil and gas industry in Nigeria accounts for about $90 \%$ of the nation's revenue and can equally be claimed to account for a similarly overwhelming proportion of the nation's environmental challenges, especially within the Niger Delta, where most of the oil is produced.

In other words, environmental policies and strategies in Nigeria significantly take into cognizance the sphere 
of oil and gas industry activities. For instance, Nigeria's development of the oil sector has been good for the country's economy; oil sector development has had an adverse impact on the country's environment. Oil extraction in the Niger Delta region has caused severe environmental degradation, owing to the legacy of oil spills, lack of environmental regulations, and government complicity during military regimes that once governed the country. Although the situation is improving with more stringent environmental regulations for the oil industry, marine pollution is still a serious problem [1]. Air pollution from natural gas flaring, exhaust emissions from the explosion in car ownership, and electricity generators continue to leave the major cities of Nigeria shrouded in smog.

The various policies and strategies of Environmental Policies and Strategies in Nigeria Oil and Gas Industry have therefore evolved almost at the same pace with the evolution of the Nigerian oil and gas industry. Consequently, it can safely be inferred that the Environmental Policies and Strategies in Nigeria Oil and Gas Industry development have preceded other sectors in terms of its content and targeted effects in combating the environmental consequences of the industry. Considering this fact, the natural assumption should be that the Environmental Policies and Strategies in Nigeria Oil and Gas Industry should be sophisticated and highly developed in terms of achieving the set goals and objectives guiding their formulations. However, this is not exactly the case, as the oil and gas industry in Nigeria as of today stands out clearly as the most bedeviled of all sectors. The undisputable controversial issues associated with the industry in terms of its adverse environmental consequences can hardly ever be adequately captured in print. The numerous oil spills for decades that have remained largely un-cleaned and un-remediated have resulted in globally acclaimed hydrocarbon impacted environmental disaster such as the UNEP report of 2011 on crude oil impacted sites in Ogoni land. Perhaps the Ogoni incident came to international acclaim mostly because of the activism of MOSOP. In other words the same scenarios of extreme crude oil pollution traverse the entire Niger Delta, but are barely reported and are therefore unknown to the environment conscious world.

The vast majority of natural gas found in Nigeria is associated, meaning that it occurs in crude oil reserves as free gas. Because many of the fields lack the infrastructure to produce the associated natural gas, it is flared. Nigeria flares more natural gas than any other country in the world, with 43 percent of its total annual natural gas production being flared. NNPC estimates that Nigerian flared natural gas accounts for approximately 20 percent of the world total. Nigeria is working to end natural gas flaring by 2008. However, Shell announced in 2004 People and Environment Annual Report that it would not be able to meet the 2008 goal of eliminating natural gas flaring. The report also remarked that "Nigeria flares more natural gas than any other countries in the world" [1]-[3] based on a survey of institutional/fisher folks respondents within the Niger Delta region, establishing that gas flaring was ranked among the highest only next to crude oil pollution for environmental factors considered to adversely affect fisheries resources within the Niger Delta region (see Table 1 and Table 2).

This is the last quarter of 2012 and Nigeria is yet to make significant progress towards achieving zero flare from where she was when the policy to end gas flaring was formulated, when this projection was made. Clearly, the preceding information is an indirect indication of environmental policies and strategies inadequacies or outright failure within the oil and gas industry of Nigeria.

\section{Developmental Stages of Environmental Laws/Regulatory Frameworks and Policies/Strategies in Nigeria}

The development and evolution of environmental laws/regulatory frame works and by extension policies/strategies in Nigeria with reference to the oil and gas industry can be divided into three major generations.

\subsection{The Pioneer/First Generation}

This covers the era from about the time the Mineral Oils (Safety) Regulation Act was passed into law in 1963 to when the when the Federal Environmental Protection Agency Decree was enacted in 1988 by the then Military government that held sway at both the state and Federal levels.

The second generation: this can be considered as the era between 1988 when the toxic waste dump in Koko Delta state not only lead to the enactment of the FEPA decree, but also influenced a heightened level of environmental consciousness and activism in the country to about 2010 when the Local Content Act (LCA) was passed.

The third/emerging generation: this is regarded to cover the pre-2010 LCA passage into law, through the un- 
Table 1. Ranking of environmental pollutants severity on fisheries resources in Niger delta by institutions.

\begin{tabular}{|c|c|c|c|c|c|c|c|c|c|c|c|c|}
\hline $\mathrm{S} / \mathrm{N}$ & Causal Factors & 1 & 2 & 3 & 4 & 5 & 6 & 7 & 8 & 9 & Score & Rank \\
\hline 1 & Incidence of pollution & 59 & 20 & 6 & 10 & 10 & - & - & - & - & 207 & 1 \\
\hline 2 & Gas flaring & 31 & 40 & 6 & 18 & 10 & - & - & - & - & 251 & 2 \\
\hline 3 & Industrial pollution & 10 & 21 & 20 & 31 & 23 & - & - & - & - & 351 & 3 \\
\hline 4 & Thermal pollution & 5 & 9 & 32 & 36 & 20 & 3 & - & - & - & 368 & 4 \\
\hline 5 & Erosion & - & 15 & 20 & 10 & 30 & 30 & - & - & - & 460 & 5 \\
\hline 6 & Siltation & - & - & 11 & - & 20 & 40 & 33 & 1 & - & 612 & 6 \\
\hline 7 & $\begin{array}{l}\text { Physical obstruction of water } \\
\text { ways by waste and equipment }\end{array}$ & - & - & - & - & 2 & 32 & 41 & 20 & 10 & 739 & 7 \\
\hline 8 & Sewage pollution & - & - & - & - & - & - & 21 & 50 & 34 & 847 & 8 \\
\hline 9 & Flooding & - & - & - & - & - & - & 10 & 34 & 61 & 891 & 9 \\
\hline
\end{tabular}

Source: Akankali and Abowei [2].

Table 2. Ranking of environmental pollutants severity on fisheries resources in Niger delta by fisher folks.

\begin{tabular}{|c|c|c|c|c|c|c|c|c|c|c|c|c|}
\hline $\mathrm{S} / \mathrm{N}$ & Causal Factors & 1 & 2 & 3 & 4 & 5 & 6 & 7 & 8 & 9 & Score & Rank \\
\hline 1 & Incidence of pollution & 304 & 220 & 206 & 85 & 75 & & & & & 2073 & 1 \\
\hline 2 & Gas flaring & 301 & 240 & 186 & 103 & 70 & & & & & 2101 & 2 \\
\hline 3 & Industrial pollution & 220 & 201 & 200 & 171 & 108 & & & & & 2446 & 3 \\
\hline 4 & Thermal pollution & 75 & 119 & 122 & 150 & 160 & 224 & & & & 3423 & 4 \\
\hline 5 & Erosion & & 120 & 120 & 160 & 230 & 260 & & & & 3950 & 5 \\
\hline 6 & Siltation & & & 66 & 130 & 134 & 140 & 200 & 230 & & 5468 & 6 \\
\hline 7 & $\begin{array}{l}\text { Physical obstruction of water } \\
\text { ways by waste and equipment }\end{array}$ & & & & 60 & 67 & 116 & 196 & 221 & 240 & 6561 & 7 \\
\hline 8 & Sewage pollution & & & & 44 & 50 & 150 & 200 & 221 & 235 & 6550 & 8 \\
\hline 9 & Flooding & & & & & 4 & 10 & 233 & 228 & 425 & 7360 & 9 \\
\hline
\end{tabular}

Source: Akankali and Abowei [3].

folding Petroleum Industry Bill (PIB) scenario which certainly portends prospective radical reviews of the oil and gas industry environmental policies till date.

\subsection{The First/Pioneer Generation}

This assertion on generational delineation of environmental laws/regulatory frame works and by extension policies/strategies is collaborated by the opinion of [4] affirming that "Environment legislation in Nigeria can be viewed broadly under two time-related categories. First, is the legal regime, which existed in the years, preceding 1988? The other consists of particular legislation, consequent guidelines and standards, and regulation introduced since the creation of the Federal Environmental Agency by Decree No. 58 of 1988”.

The pre-1988 period was characterized by certain features. Principal among these was the near-total lack of public awareness concerning environmental protection and development. Issues as biodiversity, conservation, effluent limitations, pollution abatement and sustainable development of Nigeria's natural resources did not form part of the general public discourse. At the official level, there seemed a slow realization of the interdependence of environment and development. This was underlined by the absence of a deliberate national policy aimed at protecting the environment while ensuring the conservation and sustainable use of natural resources. The absence of such deliberate policy naturally meant the non-existence of an agency entrusted with the responsibility for the protection and the development of the environment.

Reference [5] reported that the petroleum industry is a complex combination of interdependent operations, in- 
cluding exploration and production operations, the processing of the crude into consumer products, transportation and marketing activities. At each stage of operations, gaseous, liquid and solid waste materials are produced and discharged. These can adversely affect the air, water and soil media if not properly discharged and controlled. As a result, there has been a deliberate documented effort as far back as in the 1960's, to ensure a defined pathway and strategy for managing the myriad of environmental challenges facing the Nigerian oil and gas industry. A review of these pioneering laws/regulatory frame work that has over the years lead to the development of the various policies and strategies used in managing the adverse environmental problems of the Nigerian oil and gas sector is reported as follows [5]:

"Pollution control regulations in the oil and gas operations are governed by the Principal legislation of Petroleum Act 1969. The regulations are made pursuant to Section 8 (i) b (iii) of the Petroleum Act 1969 which empowers the Minister of Petroleum Resources to make regulations for the prevention of pollution of water courses and the atmosphere.

Some of the specific regulations include:

- The Petroleum (Drilling and Production) Regulations 1969, Sections 25 and 36;

- The Mineral Oils (Safety) Regulation, 1963, Part III Section 7 and Part IV Sections 44 and 45;

- The Petroleum Regulations 1967; the Oil in Navigable Waters Decree No. 34/Regulations 1968;

- The Oil Pipeline Ordinance Cap 145 of 1956 as amended by the Oil Pipeline Act 1965, Section 17 (3) and;

- The Petroleum Refining Regulations 1974, Section 43 etc.

Authority exists within these Decrees and Regulations, to issue licenses/permits and establish guidelines, standards and procedures for environmental control. Consequently, because of growing concern for adverse environmental impacts or damages arising from oil related pollution, the Department of Petroleum Resources in 1981 issued interim Guidelines concerning the monitoring, handling, treatment, and disposal of effluents, oil spills and chemicals, drilling muds and drill cuttings by leases/oil operators. Tentative allowable limits of waste discharges into fresh water, coastal water and offshore areas of operations were established.

The objectives of these Environmental Guidelines and Standards are as follows:

a) Establish Guidelines and Standards for the Environmental Quality Control of the Petroleum Industry taking into account existing local conditions and planned monitoring programmes.

b) Provide, in one volume, for the operator and other interested persons a comprehensive' integrated document on pollution abatement technology, guidelines and standards for the Nigerian Petroleum Industry.

c) Standardize the environmental pollution abatement and monitoring procedures, including, the analytical methods for various parameters.

In order to effectively evaluate and monitor the discharges into the environment, the petroleum industry is conveniently divided into six stages of operations namely, exploration, production, terminal operations, hydrocarbon processing, oil transportation and marketing operations. Each of the six stages of the petroleum industry has discussions on processes of operation, sources and characteristics of wastes, treatment and control of wastes, as well as monitoring, effluent limitations and standards.

It is pertinent to state that out of the three basic regulatory standards, namely, the effluent or end-of-the-pipe management practices and ambient quality standards, the first two sets of standards have been adopted while the third is being developed. The rationale is based on the fact that effluent or end-of-the-pipe standards provide some flexibility and knowledge of the type of materials to be discharged and also the choice of technology available to control pollutants. In addition, there are a lot of variations in the management practices of the petroleum industry in Nigeria. However, ambient quality standards require detailed and comprehensive ecological data that are characteristic of the Nigerian conditions, which are currently not available but are beginning to accumulate in the literature. The issuance of these guidelines and standards in no way absolves the operator or licensee to comply with other relevant legislation/regulations."

Considering the wide areas proposed to be covered by the preceding laws and regulations, it can be said to be elaborate enough for the era for which they were developed. However, realizing the that scientific environmental processes are dynamic and has actually progressed with time significantly, it became expedient that not just the laws/regulatory frame works guiding environmental protection within the oil and gas sector, but also the policies and strategies arising from them be reviewed to ensure efficiency in its environmental management systems. This is what has led to the evolution of what is considered a "second generation" of environmental laws/regulatory frame works and by extension policies/strategies. 


\subsection{The Second Generation}

This second generation of environmental laws/regulatory frame works and by extension policies/strategies (environmental management) for the Nigerian oil and gas industry is traceable to the era preceding the laws establishing the Federal Environmental Protection Agency in 1988. This phase is predicated on certain global emerging environmental principles, policies and strategies of the era. The Nigerian national environmental policies and strategies derived from these principles are as outlined by [6] and they include the following:

"Nigeria is committed to a national environmental policy that will ensure sustainable development based on proper management of the environment. This demands positive and realistic planning that balances human needs against the carrying capacity of the environment. This requires that a number of complementary policies, strategies and management approaches are put in place which should ensure, among others, that:

- Environmental concerns are integrated into major economic decision-making process;

- Environmental remediation costs are built into major development projects; Economic instruments are employed in the management of natural resources;

- Environmentally friendly technologies are applied;

- Environmental Impact Assessment is mandatorily carried out before any major development project is embarked on.”

\subsection{The Third/Emerging Generation}

There is yet what should be considered a third/emerging generation of environmental laws/regulatory frame works and by extension policies/strategies (environmental management) which is expected to evolve and mature with the adoption into the Nigerian Law and full implementation of the Local Content Act (LCA)/Petroleum Industry Bill (PIB) [7], while commenting on the discussions of the Bar Association of 2010 Annual general meeting deliberations stated thus, "Local content means the development of local skills, technology transfer, use of local manpower and local manufacturing. This had become an increasingly important issue that could support the Federal Government of Nigeria to upgrade her manpower capacity, with results that benefit the government, private companies, and Nigeria's economy; hence the enactment into law on Thursday, April 22, 2010 of the Nigeria Oil and Gas Industry Content Development Act 2010 (the 'Act'). The enactment of the 'Act' seeks to increase Nigerian participation not only in oil and gas industry thereby increasing Nigerian participation in the upstream and service sectors of the Nigerian energy industry but also seeks to regulate support services in the sector as well. These support services include but are not limited to financial, insurance and legal services.”

It is important to point out that environmental service in the oil and gas industry is one of the support services so referred in the preceding paragraph. For the environmental services to be so aligned with these emerging legislations within the oil and gas industry in Nigeria (LCA and the PIB) can only be effectively and positively actualize the domiciliation in practice of the local content objectives for the environmental sector if the existing environmental laws/regulatory frame works and policies/strategies become modified or out rightly reviewed to align with the realities of the LCA and LCB objectives. This metamorphosed the environmental policies and strategies in Nigeria to the forecasted realm of third generation. As for the national environmental strategies projected by this phase of environmental management in Nigeria, the following conceptual frame work applies:

The implementation of the National Policy on the environment depends on specific actions directed towards all sectors of the economy and problem areas of the environment. Consequently, the approach to problem-solving adopted in this policy is predicated on an integrated, holistic and systemic view of environmental issues. The actions envisaged will establish and/or strengthen legal, institutional, regulatory, research, monitoring, evaluation, public information, and other relevant mechanisms for ensuring the attainment of the specific goals and targets of the policy.

It is also expected that these strategies will lead to:

- The establishment of adequate environmental standards as well as the monitoring and evaluation of changes in the environment;

- The publication of up-to-date environmental data and the dissemination of relevant environmental information;

- Prior environmental assessment of proposed activities which may negatively affect the environment or the use of a natural resource.

These policies and strategies have led to the development of certain key "environmental instruments" and in- 
stitutional organs for the general Nigeria environment and for the oil and gas industry in particular. Some of these "environmental instruments" include the EIA, EMP, EA, ESI, EER, BLS, PIA, Clean up and Remediation of crude oil impacted sites etc., The Environmental Impact Assessment (EIA) Decree No. 86 of 1992 is the most outstanding of these "environmental instruments" not just for the oil and gas Industry in Nigeria, but also for all other industries in the country. The fundamental goals and objectives of the EIA Act of 1992 as enshrined in the law are as follows [8]:

- To establish before a decision is taken by any person, authority, corporate body or un incorporated body including the Government of the Federation, State or Local government intending to undertake or authorize the undertaking of any activity that may likely or to a significant extent affect the environment or have environmental effects on those activities shall first be taken into account;

- To promote the implementation of appropriate policy in all Federal Lands (however acquired) states and local government Areas, consistent with all laws through which the goal and objective in the above paragraph " 1 " above may be realized;

- To encourage the development of procedures for information exchange, notifications and consultations between organs and persons, when proposed activities are likely to have significant environmental effects on boundary or translate or on the environment of bothering towns and villages.

Based on the goal and objectives of the EIA Act of 1992 as cited above, this became the first comprehensive piece of legislation that provided:

1) The administrative and scientific basis for developing sound and incontrovertible policies and strategies for formulating environmental policies and strategies for all facets Nigerian socioeconomic activities, including the oil and gas sector;

2) Due to requirement of publicly displaying the draft EIA reports sequel to its final approval, the legislation has indirectly helped to enhance the level of awareness of all stake holders on all the other environmental policies and strategies in the country;

3) It has also created a basis for developing a sound regulatory frame work for the total environmental management of projects impacting on the environment from project conception, through implementation to commissioning and abandonment.

\section{Principles of the Nigerian National Policy on Environment}

The fundamental principle of the Nigerian policy on environment is to ensure sustainable development based on proper management of resources, both renewable and non-renewable, which are actually the components of the environment. The dynamics of the environment makes it mandatory for careful planning and management of the resources in such a way that that the natural balance of our immediate and remote environment are not altered significantly. In order words the needs of the human population should constantly be weighed against. Appropriate policies, strategies and management techniques constitutes the vehicles through these ideals can be achieved. Some of these policies are as follows:

* Environmental concerns are integrated into major economic decision-making process;

* Environmental remediation costs are built into major development projects;

* Economic instruments are employed in the management of natural resources;

* Environmentally friendly technologies are applied;

* Environmental Impact Assessment is mandatorily carried out before any major development.

Project is embarked on.

This policy, in order to succeed must be built on the following sustainable development principles:

* The precautionary principle which holds that where there are threats of serious or irreversible damage, the lack of full scientific knowledge shall not be used as a reason for postponing cost-effective means to prevent environmental degradation;

* Pollution Prevention Pays Principle (3P+) which encourages Industry to invest positively to prevent pollution;

* The polluter pays principle (PPP) which suggests that the polluter should bear the cost of preventing and controlling pollution;

* The user pays principle (UPP), in which the cost of a resource to a user must include all the environmental costs associated with its extraction, transformation and use (including the costs of alternative or future uses forgone); 
* The principle of intergenerational equity which requires that the needs of the present generation are met without compromising the ability of future generations to meet their own needs;

* The principle of intra-generational equity which requires that different groups of people within the country and within the present generation have the right to benefit equally from the exploitation of resources and that they have an equal right to a clean and healthy environment.

\section{Strategies for Implementing Environmental Policies and Strategies in Nigeria}

Until recently, the issue of environmental strategies could be said to be completely sidelined in our policy formulations. It may not even be entirely wrong to affirm that even up till now that the nation's oil and gas industry still lacks a holistic oil and gas strategic development plan. Aside from the national oil spill contingency plan activated by NOSDRA in 2011, other aspects of the oil and gas industry lacks well detailed strategic plan. The development of a strategic plan for the industry is necessary to spur the level of efficiency for the environmental laws and policies were crafted to achieve. However, the fundamentals of the principles of the strategies currently in place for the sector, is captured in the following paragraph.

"The implementation of the National Policy on the environment depends on specific actions directed towards all sectors of the economy and problem areas of the environment. Consequently, the approach to problem-solving adopted in this Policy is predicated on an integrated, holistic and systemic view of environmental issues.

The actions envisaged will establish and/or strengthen legal, institutional, regulatory, research, monitoring, evaluation, public information, and other relevant mechanisms for ensuring the attainment of the specific goals and targets of the policy.

It is also expected that these strategies will lead to:

a) The establishment of adequate environmental standards as well as the monitoring and evaluation of changes in the environment;

b) The publication of up-to-date environmental data and the dissemination of relevant environmental information;

c) Prior environmental assessment of proposed activities which may negatively affect the environment or the use of a natural resource.”

\section{The Institutional Structure of Environmental Administration in Nigeria}

DPR which has always been there from the inception of its creation till date was the main institutional agency that formulated and implemented environmental policies and strategies within the first generation of environmental policies and strategies development for the oil and gas industry in Nigeria. The DPR as a fore most regulator of the oil and gas industry in Nigeria is still very much relevant in discharging its statutorily assigned role of ensuring adequate compliance by operators to environmental guide lines and standards.

The Institutional organs under the second generation of environmental policies and strategies development in Nigeria included the defunct Federal Environmental Protection Agency (FEPA) which became subsumed into the Federal Ministry of Environment with the subsequent creation of the latter in 1999 by the civilian administration of retired General Olusegun Obasanjo. By the creation of the Federal Ministry of Environment it could be said that the Nigerian government had accorded environmental matters as it relates to the oil and gas sector and all the rest sectors indeed, the highest institutional status and priority. This meant that issues of environmental legislations, policies and strategies were considered at the highest administrative organ of the country, which is the Federal Executive Council. This a highly welcomed development for enhancing environmental policy and strategy issues especially in the oil and gas industry.

However, over the years it was realized that the Federal Ministry of Environment was bugged down with a lot of bureaucratic bottlenecks that made effective implementation and enforcement of environmental legislations cumbersome and highly inefficient. Consequently, the National Oil Spill Detection and Response Agency (NOSDRA) and the National Environmental Standards Regulatory and Enforcement Agencies were created in 2006 and 2007 through Acts No. 15 and 12 respectively. Whereas NOSDRA was to focus exclusively on regulatory functions of the oil and gas sector as regards spill detection/response and other environmental pollution arising from oil production, NESREA was focused on ensuring standards and enforcement of relevant environmental laws in all facets of Nigeria socio-economic life. The creation of these agencies under the supervision of the Federal Ministry of Environment has helped tremendously in ensuring that the content of environmental 
policies and strategies in Nigeria is not only enriched, but also that its implementation has become greatly enhanced over the recent past years. However, these agencies are generally poorly staffed, ill equipped and grossly underfunded. Consequently, their activities are far from actually impacting a significant bite on the challenges of significantly transforming the environmental policies and strategies of the nation from being merely theoretical to practicable concepts. Nigeria Maritime Administration and Safety Academy (NIMASA) also has as one of its core mandate the protection of the Nigerian Marine Environment.

The Ecological Fund Office (EFO) is yet another institution that was created in year 2003, apparently to constitute a viable source of funding the numerous ecological and environmental problems facing the nation. The precise role of the EFO as it relates to environmental policies and strategies of the oil and gas sector been made lucidly manifest in her vision and mission statements;

"Ensuring the effective coordination and monitoring of the implementation of Government policies and programmes as it affects Ecological Fund and projects, in all spheres of our national life for the development of the country and the benefit of our citizenry"-Vision statement.

"To serve as the strategic vehicle for effective communication, co-ordination and monitoring, as it affects Ecological Fund and projects, in compliance with government policies and programmes as they affect public and private sectors of the economy in the best tradition of political and public service loyalty"-Mission statement.

Even though the polluter pays principle largely operates in the oil and gas industry as an environmental policy/strategy, it is not absolutely practicable. Major reason for this flaw is that the Nigerian oil gas sector is usually a joint venture between the Nigerian government and the core investing corporate entity. It is therefore often very difficult for the government interest, mostly represented by the NNPC to channel parts of her own share of the oil revenue in ensuring compliance to environmental standards and guidelines of the Industry. In this regard, of paramount importance is the issue of exclusively Nigerian government owned and operated facilities such as Petroleum refineries, Tank farms, Oil bunkering jetties and Pipelines that has constituted a significant source of oil pollution. Although the EFO is currently funding some remediation projects in NNPC refineries, the process of accessing and applying the fund is rather rigorous and cumbersome.

Another set of institutions involved in formulating and implementing environmental strategies and policies for the oil and gas industry include the various state environmental protection agencies/state ministries of environment, especially for the oil producing states within the country. This development has often times resulted in conflict of interest and unnecessary duplication of policies and strategies for the industry. For example, the rivers state government launched its own policy document on the environment in the year 2006, called the "Rivers Green Book". According to [9] a consultative and policy making forum called the National Council on Environment was created to promote cooperation, coordination and harmonization of policies and implementation of enforcement strategies between the Federal and States EPAs as well as among the State EPA's themselves. About $60 \%$ of the States now have autonomous EPAs while the remaining operates environment units either under the Ministry of Works and Housing or Ministry of Health. The issue of conflicts still persists.

The last category of institutions driving environmental policies and strategies for the oil and gas industry are the NGO's and the professional bodies. Even though this category of institution is contributing meaningfully to the process, their roles are barely recognized. Especially, the professional body involvement in policy and strategy development for the oil and gas sector is currently not streamlined. Unlike most other professions such as law, engineering, accounting, surveying, architecture to mention but a few where the law recognizes appropriate professional bodies. The environment sector lacks any of such bodies currently. However, it is important to note that the Environmental Managers Association of Nigeria (EMAN) as presently constituted is the ideal body that should be so empowered as the council to regulate environmental practice in Nigeria. Figure 1 shows the current organizational structure of environmental administration in Nigeria.

\section{Gains of Environmental Policies and Strategies in Nigeria}

Environmental policies and strategies development for the oil and gas industry in Nigeria have engendered so many gains for the Nigerian environment. Especially, from its second generation, which is the post 1988 period, viz.

The first major gain that environmental policies and strategies development brought to bear within the oil and gas industry is that it leads to the massive creation of environmental awareness, especially among the local oil 


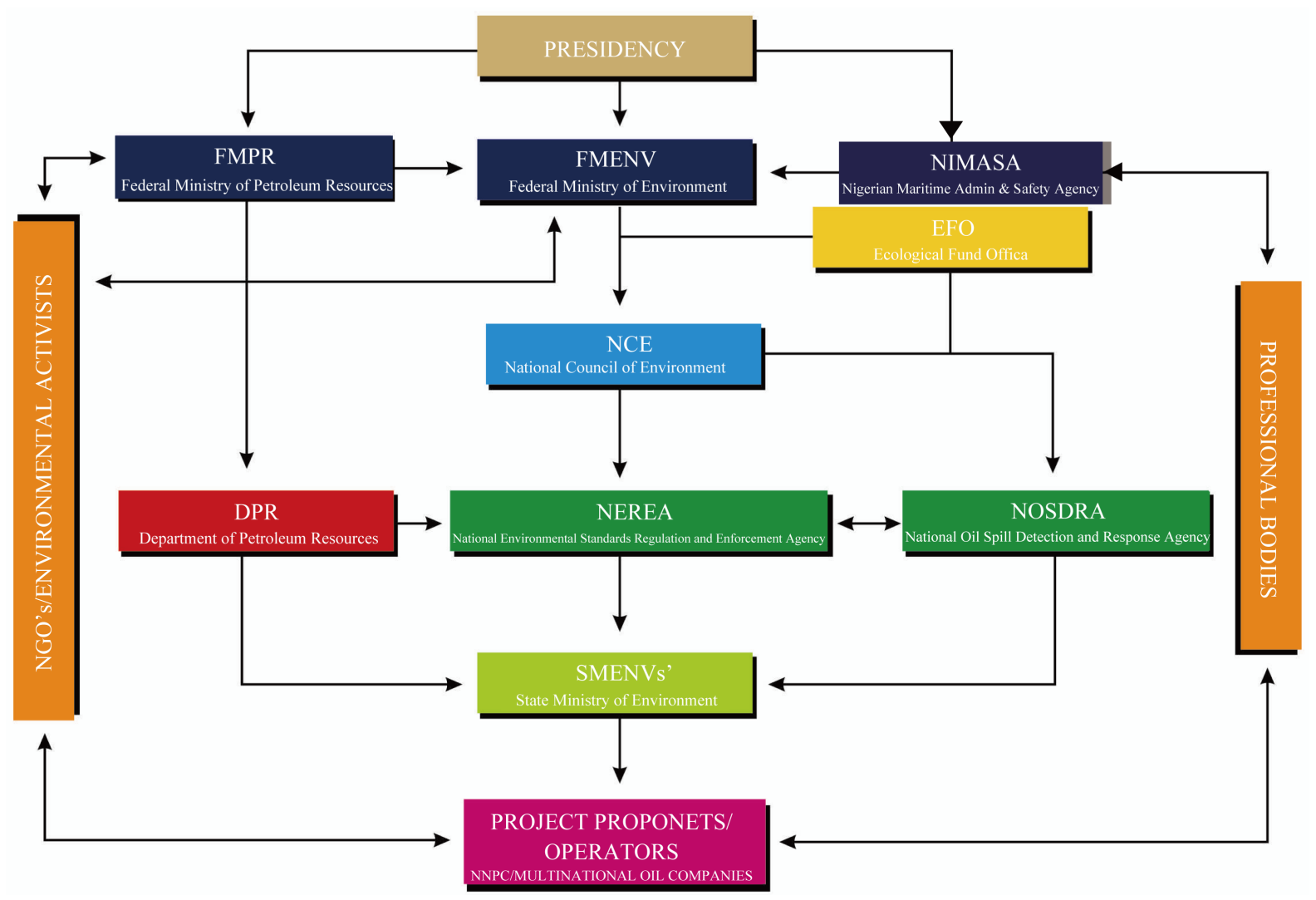

Figure 1. The current structure of environmental administration in Nigeria.

producing communities. They bear the greatest brunt of the adverse impact of oil pollution, yet they were largely uninformed of their right to seek redress. On the part of the operators, the awareness that they were responsible for the adverse consequences of their activities on the environment became well spelt out and emphasized by the policies.

This point is collaborated by [4] report that stated that in 1990, when specific environmental laws and regulations were still nascent development in the general body of our laws FEPA decided on a five years moratorium in the implementation of their provisions. The move was aimed at designing and affecting a public awareness campaign in the interim, allowing industries time to make contribution to proposed regulations and also adjust and align their production method and processes to the guidelines and standards made by FEPA. At the expiration of the five years period in 1995, FEPA commenced the monitoring and enforcement of its standards, guidelines and regulations through its department of inspectorate and compliance monitoring.

The second aspect of the gains is that it became a basis for reduction of conflicts between the various stake holders in the industry. For the first time, both oil bearing communities and the operators had a good basis for litigation, where dialogue and arbitration failed to resolve issues of adverse environmental impacts, when under contention. A case in point is the Ogoni oil pollution saga as established by [10]. The report described its findings as one of the worst environmental disasters resulting from hydrocarbon exploration;

"Summary of findings of UNEP's field observations and scientific investigations found that oil contamination in Ogoniland is widespread and severely impacting many components of the environment. Even though the oil industry is no longer active in Ogoniland, oil spills continue to occur with alarming regularity. The Ogoni people live with this pollution every day. The report concludes that pollution of soil by petroleum hydrocarbons in Ogoni land is extensive in land areas, sediments and swampland. Most of the contamination is from crude oil although contamination by refined product was found at three locations."

Courtesy of the existing environmental policies and strategies in Nigeria that yielded agencies such as NOSDRA, the highly provocative and volatile issues arising from the UNEP report though not yet resolved, all stake holders in the matter have both the policy and institutional basis for healthy engagement, rather than re- 
sorting to outright violence. It may therefore be incontrovertible to assume that had the nation's environmental laws, policies and strategies been as developed and robust as they are today during the Ken Sarowiwa's era, most probably that unfortunate blood bath that wasted the life of immensely endowed Nigerians would have been avoidable.

A third gain of the current environmental policy and strategies in Nigeria is that it constitutes a critical catalyst for attracting foreign investments. This is deducible from an inference in this regard of [4], "One of the characteristics of good law is certainty". The same principle by extension can be said to be applicable to policies and strategies arising from such laws. An environmental policy and strategy for the oil and gas industry that is well articulated, encompassing and explicit in defining the responsibilities and possible liabilities in case of defaults is usually attractive to a of prospective investors. While the Nigerian situation is not yet Eldorado, it can safely be said that our environmental policies and strategies are certainly way out of the woods.

A fourth gain of the environmental policies as it affects the oil and gas industry is the attainment of an enhanced implementation/enforcement capacity. The enabling environmental legal instruments, policies and strategies essentially from the inception of FEPA created by the Decree 58 of 1988 as the Overall (unitary) body charged with the responsibility of protecting the environment in Nigeria through to the present era of NOSDRA and NESREA created by Acts No. 15 and 12 of 2006 and 2007 respectively, these agencies have become increasingly more empowered to implement environmental laws and policies within the Nigerian oil and gas industry. As observed by [9], "Specifically, the Decree establishing the Agency authorizes it to, among other things, establish and prescribe national guidelines, criteria and standards for water quality, air quality and atmospheric protection, noise levels, gaseous emissions and effluent limits etc., to monitor and control hazardous substances, supervise and enforce compliance. The Decree also gave the Agency broad enforcements powers, even without warrants, to gain entry, inspect, seize and arrest with stiff penalties of a fine and/or jail term on whosoever obstructs the enforcement officers in the discharge of their duties or makes false declaration of compliance etc.”

The preceding statement is even truer for the succeeding agencies to FEPA (NOSDRA and NESREA), given the enhanced environmental policies and strategies currently empowering them for a more effective implementation and compliance of environmental legislations and policies. Other gains attributable to the existing environmental policies and strategies for the Nigerian oil and gas industry include the chatting of a definite road map for reduction of adverse environmental practices by operators, such as gas flaring, sustainable development initiatives especially of natural resources in oil bearing communities, reduction of incidences of environmental health hazards and streamlining oil spill response procedures.

Other notable gains attributable to the prevailing regime of environmental policies and strategies for the Nigerian oil and gas industry include the chatting of a definite road map for reduction of adverse environmental practices by operators, such as gas flaring, sustainable development initiatives especially of natural resources in oil bearing communities, reduction of incidences of environmental health hazards and streamlining oil spill response procedures. An environmental response procedure that is prompt because of a policy that clearly defines who, how and when the response should be activated definitely goes a long way in reducing associated health and environmental in the industry.

\section{Challenges of Environmental Policies and Strategies in Nigeria}

The implementation of environmental policies and strategies in Nigeria is currently fraught with certain challenges, cutting across socio-economic, scientific and cultural frontiers. Some of such key challenges include:

Overlap of Authorities: Reference [10] report on assessment of Ogoni land remarked that "overlapping authorities and responsibilities between ministries and a lack of resources within key agencies has serious implications for environmental management on the ground, including enforcement”. Further to this [9] reported that "two types of role conflicts can be identified: Conflicts in Federal/States/Local Government relations and Conflicts in Environmental-Line Ministries/Agencies relations: e.g. DPR versus FEPA; NAFDAC versus FEPA; NARESLON versus FEPA. The first aspect of this challenge deals with line of authority and delineation of designated responsibilities. The second relates largely to the apparent overlap in functions of Federal Ministries/ Agencies dealing with environment resources and/or issues".

This same overlap is currently a kind of cold contention between NOSDRA and NESREA versus DPR and sometimes Urban and Town Planning Ministries, Departments and Agencies in the oil and gas industry. Due to 
rampant duplication of environmental policy functions amongst the various agencies, the process of implementation is not just cumbersome most times, also costs are unnecessarily duplicated or triplicated or even quadruplicated as the case may be. A typical example is a scenario where an environmental consultant or project proponent/operator is required as a result of the policies of the individual agencies and ministries to obtain same environmental permits in different institutions simultaneously. This is leaves the victim entity in a cross fire of huge cost burden that may influence deliberate evasion of such permits. Further effective streamlining of the functions of the various agencies in various tiers of governance is a necessary panacea to this challenge.

Inadequate access to environmental information is another challenge. Most critical stake holders in this sector, especially, the local crude oil and gas producing communities often times are ignorant of the environmental legislations and policies governing the oil and gas industry. A survey was conducted in some oil producing local government areas of Delta state to ascertain the level of access to environmental pollution information. The result is shown in Figure 2 [11].

This scenario of poor access to environmental pollution information is most likely to be typical of all oil bearing communities. When critical stakeholders are largely uninformed as the reported survey has depicted, it makes implementation of environmental policies much more difficult. This is because the understanding and cooperation of all stake holders is necessary for any policy to be successfully implemented.

Bureaucratic obstacles is another challenge posed by the present state of environmental policies/strategies in relation to the Nigerian oil and industry; delays in the release of funds for executing environmental projects as experienced with the EFO, results in compounding of the ecological problems. This is because like most other environmental problems, hydrocarbon pollutants are highly active and some of its constituents hazardous may persist for decades in the environment. An empirical example can be found in the report [10] on Ogoniland environmental assessment, "As Ogoniland has high rainfall, any delay in cleaning up an oil spill leads to oil being washed away, traversing farmland and almost always ending up in the creeks. When oil reaches the root zone crops and other plants begin to experience stress and can die, and this is a routine observation in Ogoniland. At one site, Ejama-Ebubu in Eleme local government area (LGA), the study found heavy contamination present 40 years after an oil spill occurred, despite repeated clean-up attempts”.

Thus, if the impacted sites are not promptly contained and remediated, effects spreads over time to adjourning areas. Consequently, a re-engineered policy issue in this regard that would help eliminate or reduce drastically, such damaging delays would go a long way in ensuring adequate implementation of environmental policies and strategies.

High cost/bureaucratic bottle necks of environmental instruments; the cost of implementing most of the environmental instruments such as EIA, EER, EMP, PIA, Remediation etc. is quite high. One major cause of this is not just the scientific investigation costs, but the logistics cost for multiples of agencies involved in inspec-

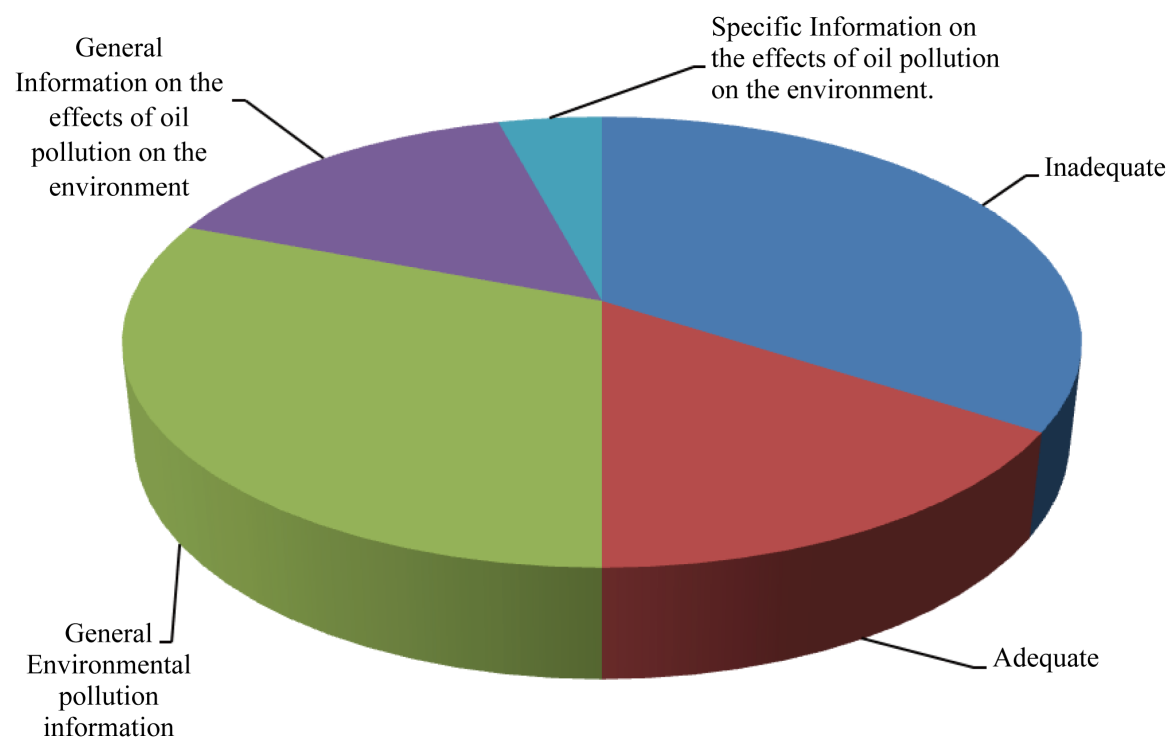

Figure 2. Level of access by artisanal fishers to environmental pollution information. 
tions and monitoring of such processes. A single monitoring exercise for a remediation project in the oil and gas industry for example currently, must as a matter of implied policy include reps from DPR, NOSDRA, relevant State agencies, the Consulting Firm and the Polluter. Undoubtedly this is a clear case of duplication of effort and unnecessary expansion of environmental bills on the aggregate for the entire economy.

Nonexistence of a defined regulatory professional body recognized by law to regulate the practice of professional environmental management in the country at this evolutionary stage of Nigeria's environmental policies and strategies is quite regrettable. Currently, several universities in Nigeria offer full option environmental management up to Doctoral levels. It has therefore become expedient that this category of professionals constitute the core body to be empowered by law to regulate professional environmental practice not just in the oil and gas industry, but across board. The current situation where professional environmental practice is an all comer affairs is highly inimical to the Nigerian environment.

Other challenges include poor environmental education, dearth of equipment and logistics for policies and strategies actualization, inadequate and poorly trained manpower, poor research and documentation of research results etc.

\section{Prospects of Environmental Policies and Strategies in Nigeria}

Though environmental policies and strategies in the Nigerian oil and gas industry are still evolving, its prospect is quite bright. Considering the extent of its evolution thus far and the level of environmental consciousness that has already been achieved in the subsector, all stake holders can be said to be more poised to cooperate in moving the process forward. Other factors that are considered to favour its prospects include the Local Content Act and the Petroleum industry bill which is currently in the works. The global heightened awareness of the impact of adverse environmental issues is also key to its prospects. The development of relevant manpower in environmental studies through establishments of specialized studies in recent times (with about eleven universities currently offering courses in different spheres of environmental management in-country) within Nigeria's Higher Institutions of learning, is yet another advantage. This is helping to develop indigenous manpower and scope of knowledge that will generally help to drive environmental policies and strategies that are largely home grown, that are most likely to be more successful.

\section{Recommendations}

Some of the recommendations needed based on this review include:

- The use of qualified professionals in the development of environmental policies and strategies is critical for effectiveness;

- In developing environmental policies and strategies for this sector, considerations for in country capacity for enforcement should be considered, in order not to render their implementation unattainable;

- Streamlining the roles of Ministries, Departments and Agencies (MDA's) involved in environmental policies and strategies in Nigeria;

- Increased funding for the MDA's are needed as a means of enhancing their capacity for implementing the existing policies and strategies effectively;

- Directing awareness creation to get to the grass roots of the stakeholders in every environment posing a challenge in the country;

- A minimum of five year mandatory review of the environmental policies and strategies for the oil and gas industry is also highly recommended for the policies and strategies to continuously address adequately the dynamic problems of the environment occasioned by the oil and gas industry activities.

\section{Conclusion}

Concerted efforts by all stake holders towards addressing most of the challenges of environmental strategies and policies in Nigeria would definitely go a long way in fast tracking environmental policies and strategies evolution as a veritable tool for appropriately addressing the numerous environmental challenges facing the oil and gas industry. This is more so against the back drop of the targeted full implementation of the Local Content Act and the proposed petroleum industry bill, if and when passed into the Nigerian law. It is hoped that when these two bills become fully operational, they will enhance further domestication of the Nigerian oil and gas industry 
environmental policies and strategies. Such a scenario shall surely elicit the cooperation of all critical stakeholders to ensure that the environmental policies and strategies work most of the time.

\section{References}

[1] Adati, A.K. (2012) Oil Exploration and Spillage in the Niger Delta of Nigeria. Civil and Environmental Research, 2, 38.

[2] Akankali, J.A. and Abowei, J.F.N. (2010) The Fisher Folks Perspective of Ranking Pollutant Sources Impacting Fisheries Resources in the Niger Delta, Nigeria. Current Research Journal of Economic Theory, 2, 41-47.

[3] Akankali, J.A. and Abowei, J.F.N. (2010) The Institutional Perspective of Pollutants Impact Severity on Artisanal Fisheries Resources in Niger Delta, Nigeria. Current Research Journal of Economic Theory, 2, 76-81.

[4] Ebomhe, S. (1998) Environmental Legislation Changes in Nigeria: What Impact on Foreign Investment? 1-8. www.geplaw.com/media/Publications/Environmental

[5] Federal Republic of Nigeria (1992) Environmental Guidelines and Standards for the Petroleum Industries in Nigeria (EGASPIN) 1991. Issued by the Department of Petroleum Resources, Revised Edition 2002, Official Gazette, Vol. 79, No. 73, 1-361.

[6] Federal Environmental Protection Agency (FEPA) (1998) Draft Revised National Policy on the Environment under the Auspices of UNDP Supported Environment and Natural Resources Management Programme for Nigeria (NIR/C3).

[7] Obozuwa, E.D. (2010) Comments on Nigerian Bar Association (NBA), 2010 Section on Business Law. Annual General Conference Held in Kaduna, Kaduna State, Nigeria. www.wali-uwais.com

[8] Federal Government of Nigeria Official Gazette (1992) E.I.A. Decree No. 86.

[9] Adegoroye, A. (1994) The Challenges of Environmental Enforcement in Africa: The Nigerian Experience. Proceedings of 3rd International Conference on Environmental Enforcement, Oaxaca, 43-54.

[10] United Nations Environment Programme (UNEP) (2011) Environmental Assessment of Ogoniland. First Published in 2011 by UNEP. www.servenigeria.com/com

[11] Akankali, J.A. and Oronsaye, J.A.O. (1997) Socio-Economic Assessment of the Impact of Crude Oil Pollution on Artisanal Fisheries in Selected Local Government Areas of Delta State, Nigeria. M.Sc. Thesis, Department of Fisheries, Faculty of Agriculture, University of Benin, Nigeria. 
Scientific Research Publishing (SCIRP) is one of the largest Open Access journal publishers. It is currently publishing more than 200 open access, online, peer-reviewed journals covering a wide range of academic disciplines. SCIRP serves the worldwide academic communities and contributes to the progress and application of science with its publication.

Other selected journals from SCIRP are listed as below. Submit your manuscript to us via either submit@scirp.org or Online Submission Portal.
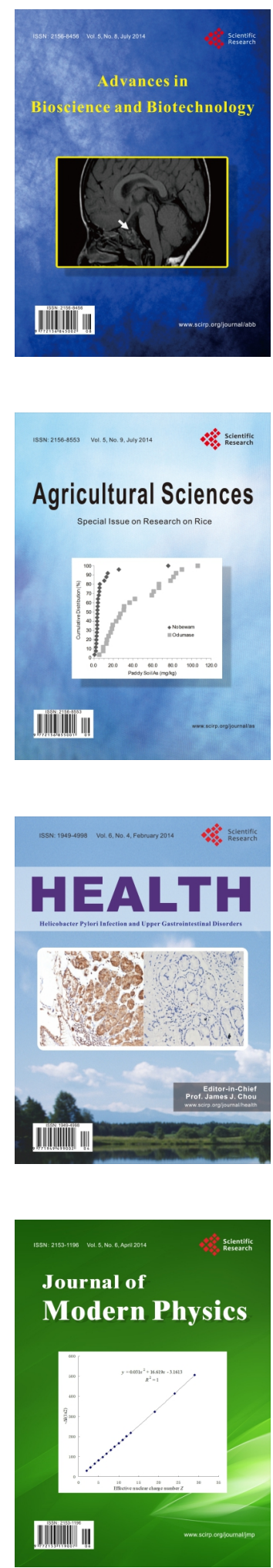
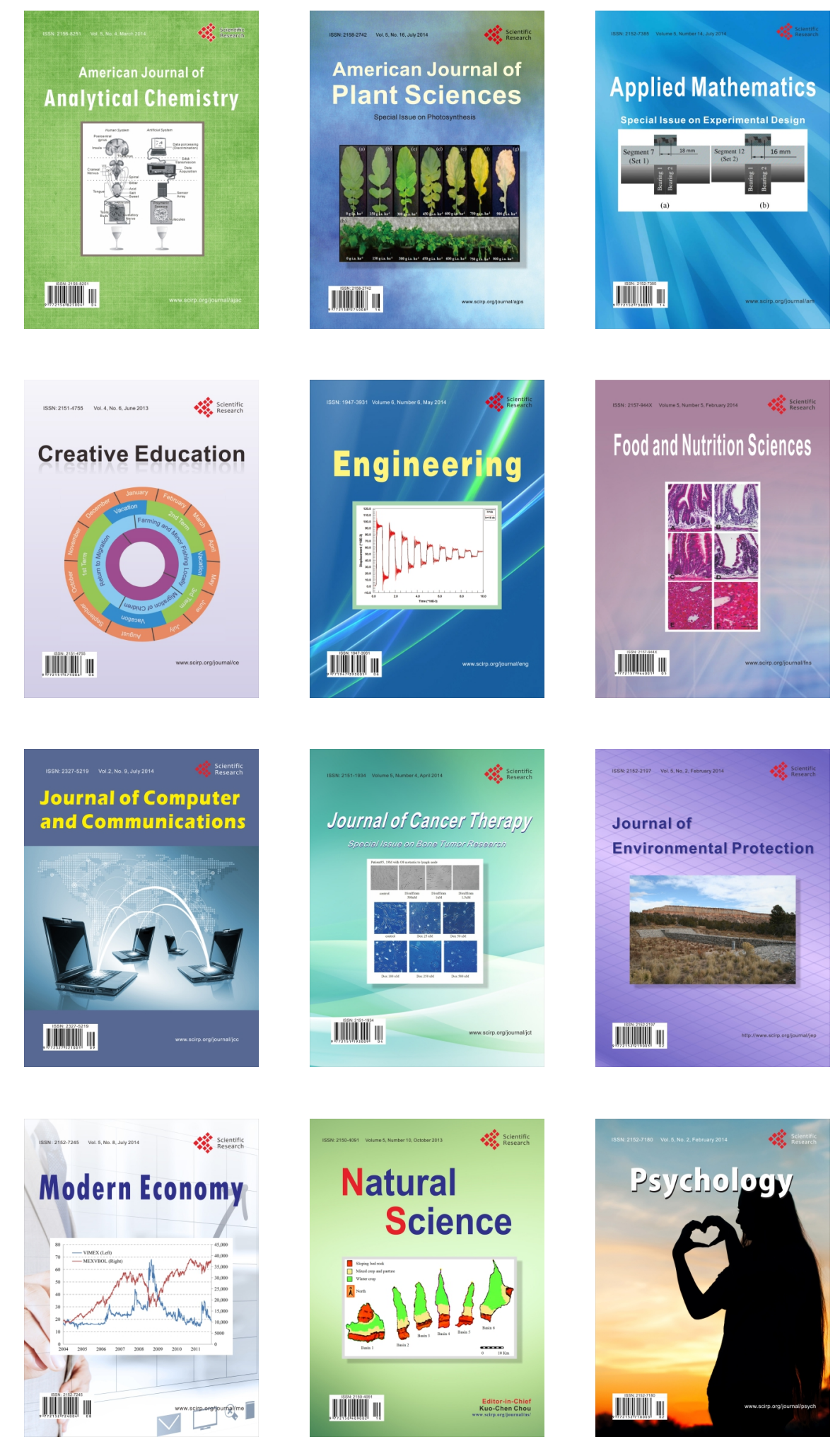